\title{
Giant Recanalized Paraumbilical Vein Mimicking Paraumbilical Hernia-Cruveilhier-Baumgarten Syndrome
}

\author{
Mehra $A^{1}$, Roshan $\mathbf{R}^{2}$, Raghuvanshi $\mathbf{S}^{3}$ \\ ${ }^{1}$ Dr Alankrita Mehra, Post graduate student,Department of radiodiagnosis, ${ }^{2}$ Dr Rakesh Roshan, Post graduate \\ student,Department of radiodiagnosis, ${ }^{3}$ Dr Sameer Raghuvanshi, Assistant Professor,Department of radiodiagnosis, \\ Peoples college of Medical sciences \& Research, Bhanpur, Bhopal, MP, India
}

Address for correspondence: Dr Alankrita Mehra, Email: dralankritamehra@ gmail.com

\begin{abstract}
Recanalized paraumbilical vein is rare but important cause of paraumbilical non pulsatile mass. We report a case of giant recanalized paraumbilical vein in known case of cirrhotic liver disease and portal hypertension mimicking as paraumbilical hernia on clinical examination. B -mode and Doppler study pointed towards the subcutaneous tortuous dilated tubular structure at paraumbilical region showing color flow and extension upto liver surface in parietal wall of abdomen. Venous blood flow demonstrated on color Doppler study. CT study used to make final diagnosis which demonstrated subcutaneous dilated tortuous opacified tubular veins at paraumbilical region extending along the parietal wall of abdomen into hepatic fissure to join portal vein branch.
\end{abstract}

Key words: Recanalized paraumbilical vein, paraumbilical hernia, Cruveilhier-Baumgarten Syndrome

\section{Introduction}

The adaptation of portal circulation to portal hypertension has been well documented both anatomically and angiographically. Numerous portosystemic collateral pathways have been demonstrated in intra and prehapatic portal hypertension. Real time sonography is accurate tool in the demonstration of these collaterals as well as in defining the site of portal venous obstruction $[1,2]$.

An important site of portosystemic venous anastamosis is around the umbilicus clinically named as CruveilhierBaumgarten syndrome - portal hypertension, prominent periumbilical veins, atrophic liver and splenomegaly $[3,4]$. We attempted to define the anatomy of dilated paraumbilical vein in patient with portal hypertension presented as paraumbilical non pulsatile mass mimicking paraumbilical hernia $[1,3,4]$.

\section{Case Report}

A 28 year old woman was referred for ultrasonography of paraumbilical hernia on clinical examination. The patient presented to the OPD with a swelling at the paraumbilical region since 1 month (figure1) and that was non pulsatile \& reducible. There was history of previous two caesarean sections. There was no other medical or surgical history.

On examination of the swelling:

- Swelling was partially reduced on lying down

- On cough reflex - increase in the size was noted

Per Abdomen:

- Palpable spleen.

Manuscript received: $18^{\text {th }}$ June 2015

Reviewed: $24^{\text {th }}$ June 2015

Author Corrected: $29^{\text {th }}$ June 2015

Accepted for Publication: $16^{\text {th }}$ July 2015 


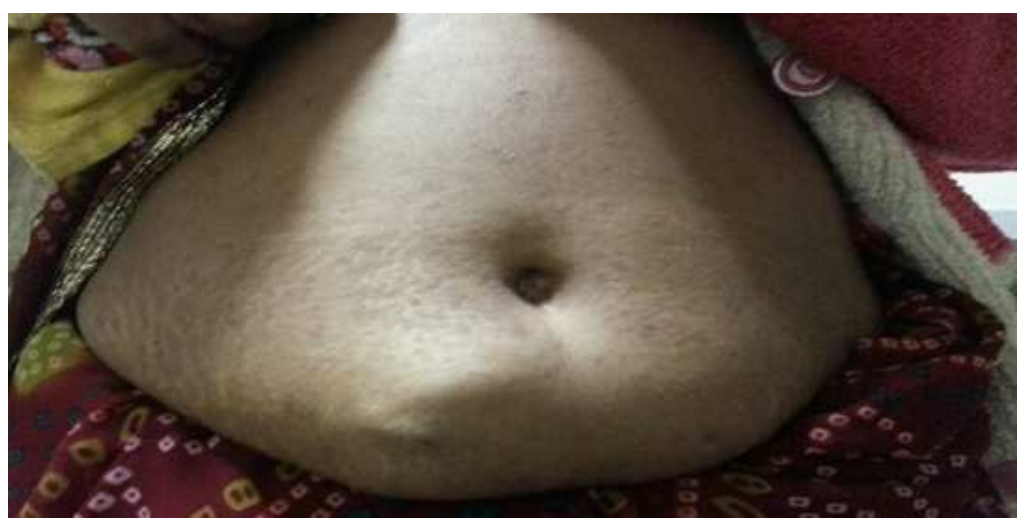

Figure 1- Right paraumblical partially reducible \& non pulsatile swelling

Sonography Findings

- Splenomegaly (figure 2)

\section{SITES OF PORTACAVAL ANASTOMOSIS}

Five sites of portal/systemic circulation :

1. Lower third of the Esophagu

2. Paraumbilical Area

3. Upper end of Anal canal

4. Retroperitonial

5. Bare area of liver

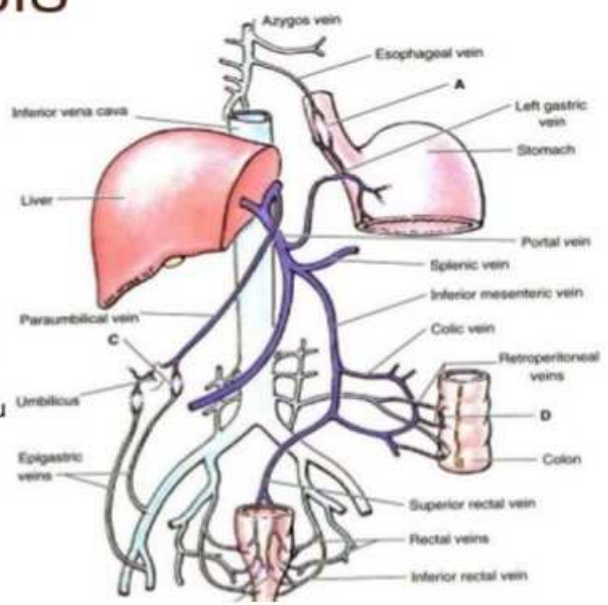

Figure 2- Ultrasound image showing Splenomegaly.

- Liver - Coarse echotexture and dilated vein along the hepatic surface (figure 3)

- Dilated and recanlised paraumbilical vein collateral in the subcutaneous fat plane appearing as a cystic lesions. (figure 4)

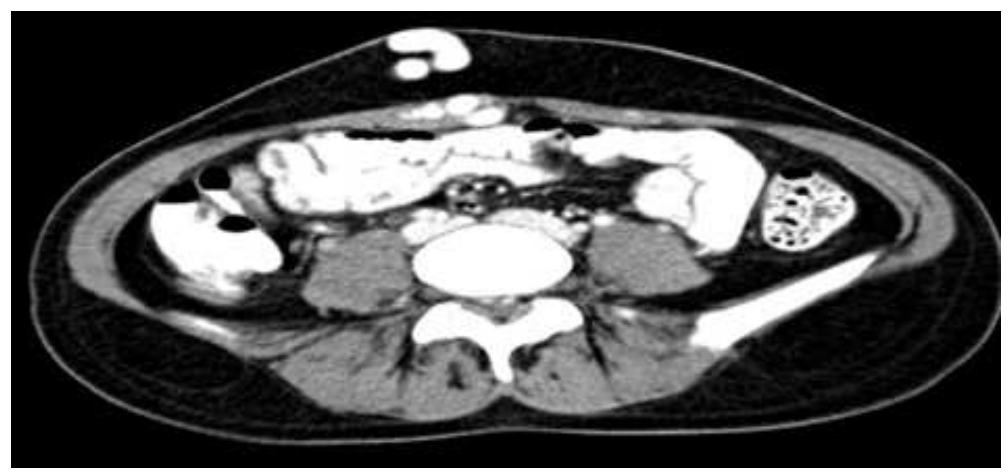

Figure 3- Ultrasound B mode \& Color Doppler image showing coarse hepatic echotexture \& dilated vein in relation to the liver. 


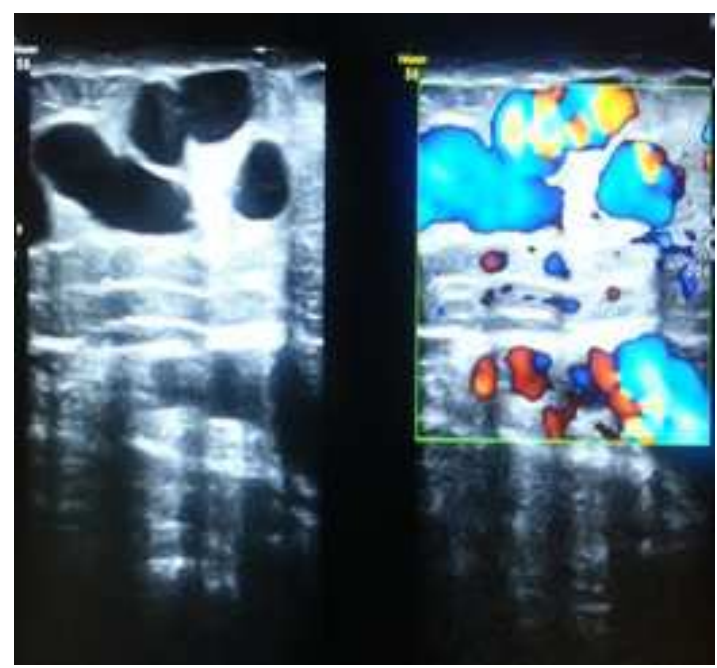

Figure 4- Color Doppler image showing multiple dilated tortuous veins at subcutaneous umbilical region

\section{Color Doppler Sonography:}

- Presence of multiple dilated subcutaneous tortuous veins at paraumblical region with formation of venous varices and venous flow on doppler study (figure 5)

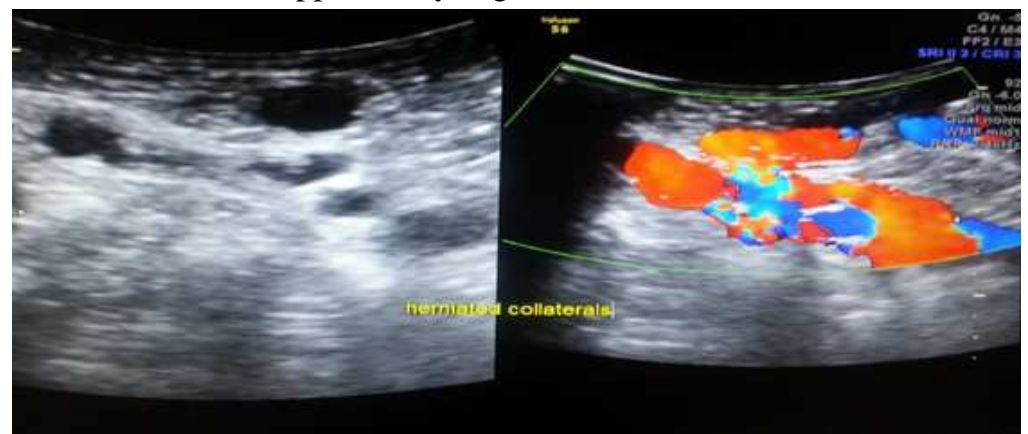

Figure 5 - Transverse color Doppler image showing multiple dilated tortuous veins in the subcutaneous plane with formation of venous varix.

- Presence of dilated opacified paraumblical collaterals (figure 6)

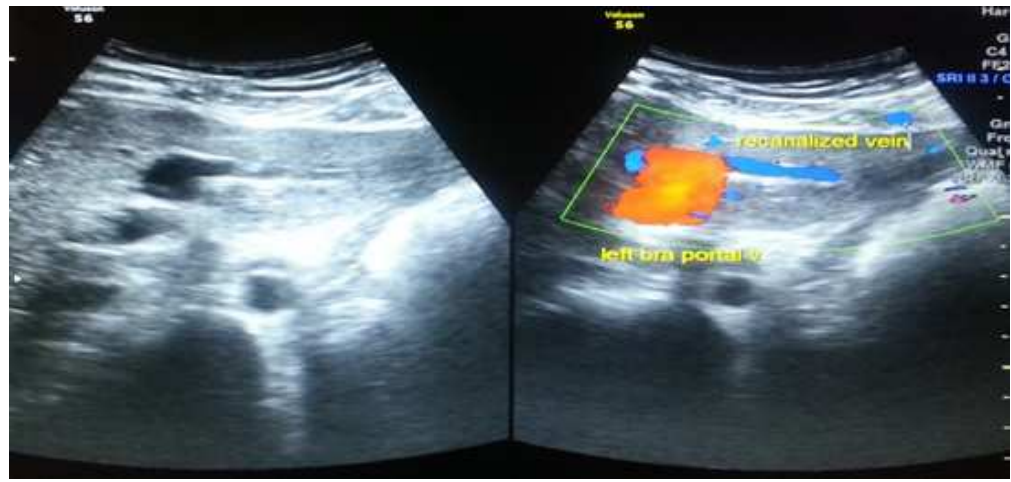

Figure 6- CT images showing opacified dilated tortuous veins in the paraumblical subcutaneous plane

Diagnosis: Multiple Dilated paraumblical collaterals in the subcutaneous plane mimicking paraumbilical hernia.

\section{Differential Diagnosis:}

Paraumbilical hernia 


\section{Discussion}

In into perinatal life, the paired vitelline veins and paired umbilical veins drains independently into the sinus venosus. Rudolph AM et al [5] described Hepatic and ductus venosus blood flows during fetal life.As liver develops it intercepts these veins and incorporated them into the sinusoids. The left paraumbilical vein maintains direct communication with the sinus venosus via ductus venosus. The right umbilical vein disappears early in the perinatal development. The right and left vitelline veins develop into portal vein. The left umbilical vein drain into left branch of newly formed portal vein In uteroupto $50 \%$ of placental blood is shunted directly into right atrium via left umbilical vein and ductus venosus. Doehner GA and Aousselot LM et al [6,7] described the portal venous system and its roentgen anatomy.

After birth, the umbilical vein atrophies within the falciform ligament and forms ligamentum teres. The ductus venosus becomes the ligamentum venosus. Para umbilical collateral veins accompany the ligamentum teres in the falciform ligament of the liver, form anastamosis with the systemic venous system by various routes and carry portal venous blood away from the liver.

In portal hypertension shunting of blood away from the liver into the systemic venous system provides a mechanism of reducing portal venous pressure. Juttner $\mathrm{HU}$ and Bergstrand I et al $[1,8]$ described the findings of portal hypertension in cirrhotic liver disease. Spontaneous portal-systemic collateral pathways (varices) (FIGURE 7) develop via enlargement of pre-existing anastomoses between the portal and systemic venous system.

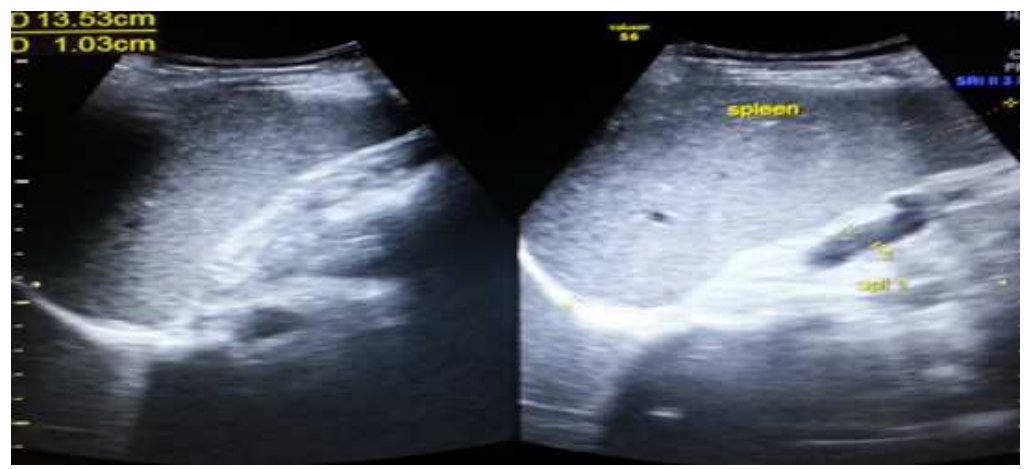

Figure 7- Anatomical diagram Spontaneous portal-systemic collateral pathways (varices)

The main sites of collaterals as follows

Distal oesophagus: Left gastric (coronary) vein \& short gastric veins to distal oesophageal veins Splenorenal (lienorenal) ligament: Splenic vein to left renal vein -splenorenal shunt veins (haemorrhoids).

Retroperitoneum: Superior mesenteric veins to retroperitoneal/lumbar veins to the inferior vena cava.

Anterior abdominal wall: Paraumbilical vein to epigastric vein near umbilicus

Anal canal: Superior rectal vein (from inferior mesenteric vein) to upper anal canal. The recanalisation of paraumbilical collateral veins with hepatofugal flow (velocity, $>5 \mathrm{~cm} / \mathrm{sec}$ ) on Doppler sonography is a sign of portal hypertension and has $100 \%$ specificity.Lavoie P, Kane RA, Dokmeci AK et al described the sonographic findings and measurements in portal hypertension $[2,9,10]$.

Recanalized large paraumblical vein in the subcutaneous plain often present as paraumblical non pulsatile mass in cases of portal hypertension secondary to cirrhotic liver disease and clinically named as Cruveilhier-Baumgarten syndrome. Armstrong EL \& Abraham et al described [3,4] described this syndrome. Acquired umbilical hernias occur more commonly in women, mostly after childbirth. Hernias classically result of obesity, multiple pregnancies, weak abdominal walls, intraabdominal masses, liver cirrhosis, and ascites

Although rupture of an umbilical hernia in a patient with ascites is an important, and is fatal complication and surgical repair is often recommended. 


\section{Conclusion}

Recanalized paraumbilical vein is rare but important cause of paraumbilical non pulsatile mass formation which can mimic paraumblical hernia on clinical examination. Chronic liver disease with portal hypertension is the cause of recanalization of paraumblical vein which is part of porto-systemic collateral formation. Sonography and Doppler study often the first imaging modality use to diagnose the recanalization of paraumblical vein. CT study used to make final diagnosis.

\section{Acknowledgments}

The authors are thankful to their junior colleagues.

\section{References}

1. Juttner HU, Jenney JM, RaIls PW, Goldstein LI, Reynolds TB. Ultrasound demonstration of portosystemic collaterals in cirrhosis and portal hypertension. Radiology. 1982 Feb;142(2):459-63.

2. Kane RA, Katz 5G. Spectrum of sonographic findings in portal hypertension: a subject review and new observations. Radiology. 1982 Feb;142(2):453-8.

3. Eugene, Armstrong EL, Adams WL, Tragerman U, Townseed EW. Cruveilhier-Baumgarten syndrome: review of literature and report of 2 additional cases. Ann Intern Med Jan 1942 16(1):113-151.

4. Abraham As, Atkinson M. Cruveilhier-Baumgarten Syndrome. Ann Intern Med May 1965 62(5):1045-1049.

5. Rudolph AM. Hepatic and ductusvenosus blood flows during fetal life. Hepatology. 1983 Mar-Apr;3(2):254-8.

6. Doehner GA, Ruzicka FF, Hoffman G, Rousselot LM. The portal venous system: its roentgen anatomy. Radiology 1955 May 64:675- 689.

7. Gunther A,Doehner, Francis, Ruzika, Louis, Rousselot LM, Hoffman G. The portal venous system: on its pathological roentgen anatomy. Radiology. 1956 Feb;66(2):206-17.

8. Bergstrand I, Eckman CA. Portal circulation in portal hypertension. Acta Radiologica Jan 1957; 47 (1): 1-22 .

9. M Lafortune,DMarleau, G Breton, Lavoie P, Huet PM. The portal venous system measurements in portal hypertension Radiology. 1984 Apr;151(1):27-30.

10. Dokmeci AK, Kimura K, Matsutani, et al. Collateral veins in portal hypertension: demonstration by sonography. AJR Am J Roentgenol. 1981 Dec;137(6):1173-7.

\section{How to cite this article?}

Mehra A, Roshan R, Raghuvanshi S. Giant Recanalized Paraumbilical Vein Mimicking Paraumbilical HerniaCruveilhier-Baumgarten Syndrome. Int J Med Res Rev 2015;3(6):655-659. doi: 10.17511/ijmrr.2015.i6.113. 